\title{
Analysis of Core Competency Required for the Managerial Work Force of Small and Medium Enterprises in Taiwan
}

\author{
Chien-Hua Shen ${ }^{1}$, Chun-Mei Chou ${ }^{2}$, Hsi-Chi Hsiao ${ }^{3}$, Yu-Je Lee ${ }^{4}$ \\ ${ }^{1}$ Department of Business Administration, TransWorld University, Yunlin, Taiwan, China; ${ }^{2}$ Institute of Vocational \& Technological \\ Education, National Yunlin University of Science \& Technology, Yunlin, Taiwan, China; ${ }^{3}$ Graduate Institute of Business and Ad- \\ ministration, Cheng Shiu University, Kaohsiung, Taiwan, China; ${ }^{4}$ Takming University of Science \& Technology, Taipei, Taiwan, \\ China. \\ Email: shen17@ms51.hinet.net, choucm@yuntech.edu.tw, hchsiao@cc.ncue.edu.tw,pyj.abcd@msa.hinet.net
}

Received 2013

\begin{abstract}
This study aims to probe into the core competencies, as should be possessed by the managerial work forces of firms, from the perspective of employers' in small and medium enterprises. The findings can serve as references for planning core courses of employee training and labor employment. Based on the research purposes, this study adopted revised DACUM, conducted literature review, and applied a questionnaire survey. The subjects were the members of SMEs Honor Instructor Association of Ministry of Economic Affairs, Taiwan, and the Society of Management Science. Random sampling was used, with the number of employees as the units. The valid return rate was $24.2 \%$. After testing goodness of fit of K-S single samples, this study found that a corporate management work force should have 11 items of core competency, and 35 items of secondary competency.
\end{abstract}

Keywords: Small and Medium Enterprises; Enterprise Training; Core Competency

\section{Introduction}

\subsection{Research Background and Motives}

Upon a goal-oriented course design concept, course design should consider the needs of the employment units. Although the government of Taiwan estimates the demand for labor every year, it does not provide specific data regarding the quality and quantity of competency required by managerial workers as the references for course design [1]. Currently, competency analysis of the management work force in Taiwan is mostly based on literature reviews and generalization. However, because of changing environments and the progress of technology in recent years, it is necessary to probe into the changing demands for competency of managerial labor in business circles, and the quality and quantity of educational content in educational circles.

As suggested above, due to the progress of technology information, lifelong learning and self-oriented learning capability become more important. In other words, learning refers to the learning skills of students, rather than simple knowledge learning. Knowledge learning should be combined with the students' career developments in order to facilitate both a learning base and capability. Thus, in schools, in addition to the instruction of general and professional knowledge, it is more important to enhance the students' core competency in order that they can adapt to environmental changes, which will also satisfy individual needs for career development and demands of work forces in business circles [2]. Therefore, by competency analysis-revised DACUM (Developing A Curriculum), seen from the employers' perspective, this study constructs the core competencies required by corporate management labor forces to function as the criterion for course design in technological institutes, which is the main research motive.

\subsection{Research Purposes}

This study aims to construct the core competencies of corporate management labor from the employers' perspectives and abilities analysis. The research purposes are as shown below:

(1) To establish core competencies, as should be possessed by corporate management work forces.

(2) To construct the secondary competencies of the core competencies of corporate management.

\section{Research Method}

\subsection{Research Subjects}

According to the research purposes, this study adopted 
competency analysis -revised DACUM (Developing A Curriculum) and a questionnaire survey. The subjects were as shown below:

1) Competency analysis -revised DACUM: this study treated the members of SMEs Honor Instructor Association of Ministry of Economic Affairs, Taiwan and on-the-job members of the Chinese Management Association as subjects. By purposive sampling, ten research samples are selected.

2) Questionnaire survey: in order to probe into the goodness of fit of core competencies, this study treated the members as the employers in the central Taiwan SMEs Honor Instructor Association of Ministry of Economic Affairs, Taiwan, and Society of Management Science as the subjects, about 1200 people. After cording by random sampling, and according to the research findings of Krejcie \& Morgan (1970), 200 samples were selected.

\subsection{Research Tools}

By self-designed questionnaire, this study collected the samples' views regarding goodness of fit of the core competencies of corporate management, as constructed by this study. The questionnaire content was based on competency analysis and job market developments of different countries. Questionnaire contents and construction of reliability and validity are as described below.

1) Content of questionnaire: Questionnaire survey of goodness of fit of "core competencies of corporate managerial work force" includes two parts:

a) Basic information

(1) The subjects' gender: Males and females.

(2) Total number of employees: According to small and medium enterprises, as defined by the Ministry of Economic Affairs of Taiwan, distribution numbers are as follows, 1.5 people, 6-20 people, 21-50 people, 51-100 people, and above 100 people.

b) Content of questionnaire

Core competencies are divided into 12 items, with 38 sub-abilities. The questionnaire is based on a five-point self-reported scale, where 1-7 indicates the goodness of fit of the abilities, as suggested by the samples.

2) Construction of reliability and validity

a.) Reliability

Upon the questionnaire design, the researcher treats the members of SMEs Honor Instructor Association in Yunlin of Taiwan, and the employers in the Industrial Park of Douliu as the subjects. There are 100 pretest questionnaires distributed, with 63 returned. After testing internal consistency, Cronbach's $\alpha$ is 0.86 .

\section{b) Validity}

Upon the questionnaire design, this study invited two employees of the national employment service center of the Tainan Bureau of Employment and Vocational
Training, three representatives from business circles, and two representatives from academia to review the propriety of the wording in the questionnaire in order to construct content validity for the questionnaire.

\subsection{Research Process}

1) Capability analysis

a) This study treated the members as the employers of SEMs Honor Instructor Association of Ministry of Economic Affairs Taiwan, and the Chinese Management Association as the subjects. By telephone, the researcher selected 15 subjects that had the intention to participate and could join in discussions to form the team of DACUM competency analysis.

b) The first DACUM competency analysis: prior to the conference, this study reorganized the related data as the references for participants. The members shared opinions during a 4 hour discussion, and developed 12 items of core competency.

c) The second DACUM competency analysis: based on the outcome of the first conference, in the second conference, the researcher described the expected core competencies, and conducted competency analysis on the items. The second conference lasted about 3 hours, and developed 38 items of secondary competency.

d) This study reorganized the 38 items of secondary competency, and developed the questionnaire goodness of fit regarding "core competencies of business management labor forces". On October 21, 2011, there were 200 questionnaires sent. On November 6, the first return of questionnaire was finished, with 43 returned. After the urge of return and distribution of 100 questionnaires, there were finally 88 returns. The researcher eliminated questionnaires with incomplete answered, and obtained 85 valid returns, for a return rate of $24.2 \%$.

\subsection{Data Analysis}

In order to accomplish the research purposes, this study adopts frequency distribution and goodness of fit of K-S single sample as the statistical procedure for data analysis in order to recognize the samples' consistent views regarding the capabilities goodness of fit.

Statistical significance level is set as 0.05 .

\section{Conclusions and Suggestions}

From the employers' point of view, this study aims to probe into the core competencies required by corporate managerial labor forces as the criterion for management departments of technological and vocational institutes for course planning. The conclusions and suggestions are as below. 
Table 5-1. Core and secondary competencies, as should be possessed by management labor forces.

\begin{tabular}{|c|c|}
\hline Core competencies & Secondary competencies \\
\hline Computer competency & $\begin{array}{l}\text { Basic computer use } \\
\text { Use of Word } \\
\text { Use of Excel } \\
\text { Use of database programs } \\
\text { Internet use }\end{array}$ \\
\hline Team work competency & $\begin{array}{l}\text { Team work training } \\
\text { Special project management capability }\end{array}$ \\
\hline $\begin{array}{l}\text { Knowledge management } \\
\text { capability }\end{array}$ & $\begin{array}{l}\text { Data collection } \\
\text { Data analysis capability } \\
\text { File construction of data }\end{array}$ \\
\hline $\begin{array}{l}\text { Self-oriented learning } \\
\text { capability }\end{array}$ & $\begin{array}{l}\text { Capable of learning new knowledge } \\
\text { Advanced learning intentions } \\
\text { Good learning attitude }\end{array}$ \\
\hline $\begin{array}{l}\text { Quality and cost manage- } \\
\text { ment capability }\end{array}$ & $\begin{array}{l}\text { Work planning capability } \\
\text { Concept of quality } \\
\text { Concept of cost } \\
\text { Figure management capability }\end{array}$ \\
\hline $\begin{array}{l}\text { Self-management capabil- } \\
\text { ity }\end{array}$ & $\begin{array}{l}\text { Emotional management capability } \\
\text { Career planning ability } \\
\text { Family life } \\
\text { Interpersonal relationships }\end{array}$ \\
\hline Leadership & $\begin{array}{l}\text { Conflict coping capability } \\
\text { Financial capability } \\
\text { Planning capability } \\
\text { Crisis management ability }\end{array}$ \\
\hline Work ethics & $\begin{array}{l}\text { Ethical concepts } \\
\text { Responsibility Loyalty' } \\
\text { Appearance and manners }\end{array}$ \\
\hline Communication capability & $\begin{array}{l}\text { Verbal expression capability } \\
\text { Negotiation capability }\end{array}$ \\
\hline Thinking capability & $\begin{array}{l}\text { Independent thinking capability } \\
\text { Problem-solving capability }\end{array}$ \\
\hline Language proficiency & $\begin{array}{l}\text { English proficiency } \\
\text { Japanese proficiency }\end{array}$ \\
\hline
\end{tabular}

\subsection{Research Cconclusions}

1) In small and medium enterprises, managerial work forces should possess 11 items of core competency.

By revised DACUM and questionnaire survey, according to outcomes of data analysis, corporate employers all suggested 11 items of core competency required by a management labor force: computer competency, team work competency, knowledge management capability, selforiented learning capability, quality and cost managemment capability, self-management capability, leadership, work ethics, communication capability, thinking capability, and language proficiency.

2) The 35 items of secondary core competency required by corporate management labor forces.

After revised DACUM and the questionnaire survey, according to outcomes of data analysis, the employers suggested 35 items of secondary core competencies required by a management labor force, as in Table 5-1.

\subsection{Research Suggestions}

1) To analyze the tasks of core and secondary competencies of corporate management labor forces as the references of development of teaching materials.

Regarding the 11 items of core competency and 35 items of secondary competency of corporate management labor, as constructed by this study, the researcher should conduct task analysis in order to establish the expertise, knowledge, and assignments of the capabilities, for use as the references of development of teaching materials.

2) To construct the indicators of core competency and secondary competency of corporate management labor.

By revised DACUM and collection of the employers' opinions, this study constructed 11 items of core competency, and 35 items of secondary competency, as should be possessed by corporate management labor forces. This study further developed the indicators of secondary competencies as the references for business circles to plan enterprise training courses and evaluate training effectiveness, for use as reference for technological and vocational institutes' planning core courses, and the construction of instructional goals for different subjects.

\section{REFERENCES}

[1] C. M. Chou, J. H. Shen, "Primary Study on Business Modernization Capability of the Students in Business Management Group of Technological and Vocational Institutes," Business Education Quarterly, vol. 83, pp. 2-11, 2001.

[2] D. B. Feng, "Study on Capabilities of the Graduates in Universities of Technology and Vocational Colleges", Special Project Report Authorized by National Science Council, Executive Yuan (NSC92-2413-H0003-033). Taipei: National Taiwan Normal University, 2004.

[3] Central Personnel Administration (2004). Study on Construction of Core Competency Indicators. http://ca2.cpa.gov.tw/oldweb/govinfo/92research.htm

[4] Nunes, P. \& Breene T. 2011. Reinvent your business before it's too late. Harvard Business Review. January-February.

[5] Menkes, J. (2006), "Hiring for smarts," Harvard Business Review, 82(11), 100-109 